\title{
Epigenetic Changes in Cancer and Preneoplasia
}

\author{
J.G. HERMAN \\ The Sidney Kimmel Comprehensive Cancer Center at Johns Hopkins, \\ Baltimore, Maryland 21231
}

\begin{abstract}
Recent studies have identified an increasing number of genes that are inactivated by promoter region methylation in cancer. Some of these genes were initially identified as altered genetically in cancer, but in other tumors they are silenced in association with promoter region $\mathrm{CpG}$ island methylation. New approaches for screening the genome add to this list of candidate tumor suppressor genes, and many genes regulated key pathways in cancer, including cell cycle control, DNA repair, and apoptosis. Transcription factors may also be silenced by promoter region methylation, affecting the expression of many downstream target genes and globally altering the cancer phenotype. Determining loss of expression is important in assigning functional importance to promoter region methylation for any gene. Individual cancers have alterations in many different genes, affecting many of these important pathways and contributing to the cancer phenotype. The number of genes targeted for promoter region methylation increases during neoplastic progression. These studies suggest that the epigenetic change of promoter region methylation plays a critical role in neoplastic transformation and progression.
\end{abstract}

Genetic alterations are a hallmark of human cancer and form the basis of much of what we know about cancer. However, many of the changes that are functionally relevant for the development and progression of cancer occur without changes at the nucleotide level, which is in the absence of mutation. The down-regulation of the expression of many genes has been recently found to be caused by changes in promoter region methylation, which is an epigenetic change. The $\mathrm{CpG}$ dinucleotide, which is usually underrepresented in the genome, is clustered in the promoter regions of many genes. These promoter regions have been termed $\mathrm{CpG}$ islands (Bird 1986). CpG islands are protected from methylation in normal cells, with the exception of genes on the inactive $\mathrm{X}$ chromosome and imprinted genes. This protection is critical, since the methylation of promoter region $\mathrm{CpG}$ islands is associated with a loss of expression of these genes through chromatin changes, as discussed below. The following three different alterations in DNA methylation are common in human cancer: (1) global hypomethylation, often seen within the body of genes; (2) dysregulation of DNA methyltransferase I, the enzyme involved in maintaining methylation patterns, and potentially other methyltransferases; and (3) regional hypermethylation in normally unmethylated $\mathrm{CpG}$ islands.

\section{EPIGENETIC CHANGES TARGET KEY TUMOR SUPPRESSOR GENES}

Extensive work by many investigators over the last several years has demonstrated that promoter hypermethylation commonly silences tumor suppressor genes in human cancer, serving as an alternative mechanism for the loss of tumor suppressor gene function (Baylin et al. 2001; Jones and Baylin 2002; Herman and Baylin 2003). Initial studies commonly focused on classic tumor suppressor genes, which were mutated in some cancers and may have an inherited predisposition associated with germ-line mutations. For example, the cell-cycle-regulated p16INK4a, a cyclin-dependent kinase inhibitor that regulates another tumor suppressor gene $\mathrm{Rb}$, is commonly deleted in cancers (Kamb et al. 1994). However, if it is not deleted, inactivation can occur in association with promoter region methylation (Merlo et al. 1995) and is associated with loss of gene expression. Although this growth in interest does not displace or diminish the importance of the genetic changes in cancer, in this overview I only discuss the role of epigenetic changes in cancer, specifically, promoter region DNA methylation.

\section{PROMOTER REGION METHYLATION SILENCES THROUGH CHROMATIN CHANGES}

DNA hypermethylation in the promoter region of genes is associated with loss of gene expression. By using bisulfite genomic sequencing (including cloning of individual alleles) to obtain a detailed analysis of methylation in acute leukemia, leukemia cell lines, and normal lymphocytes, evidence for the importance of methylation density was shown for p15ink4b/CDKN2B (Cameron et al. 1999a). This gene is frequently methylated in acute lymphocytic and myelogenous leukemia. The entire $\mathrm{CpG}$ island region of p15 was largely devoid of methylation in normal lymphocytes, but methylation of varying density was found in primary acute leukemia. Methylation density was generally conserved between the alleles from each sample, but marked heterogeneity for the specific $\mathrm{CpG}$ sites methylated was observed. Patterns of methylation were compared and expression was assessed with reverse-transcriptase polymerase chain reaction (RT-PCR). The density of methylation within the $\mathrm{CpG}$ island, and not any specific location, correlates best with transcriptional loss (Cameron et al. 1999a). Leukemias with methylation of approximately $40 \%$ of the $\mathrm{CpG}$ dinucleotides on each allele had complete gene silencing, with variable, but diminished, expression with less dense $\mathrm{CpG}$ island methylation. 
Promoter region methylation is associated with silencing through changes in chromatin configuration and the histone code. Densely methylated DNA associates with transcriptionally repressive chromatin characterized by the presence of underacetylated histones. Optimal reexpression of silenced genes is accomplished by inhibition of both DNA methyltransferase and histone deacetylases (Cameron et al. 1999b). Using detailed mapping by chromatin immunoprecipitation (ChIP), clearly defined zones of deacetylated histone H3 plus methyl-H3-K9 surround a hypermethylated, silenced promoter, which, when unmethylated and active, is embedded in methyl-H3-K4 and acetylated H3 (Fahrner et al. 2002). Inhibiting DNA methyltransferases, but not histone deacetylases, leads first to promoter demethylation, second to gene reexpression, and finally, to complete histone code reversal (Fahrner et al. 2002). These studies link the changes in DNA methylation to associated changes in the histone code associated with gene silencing and demonstrate the importance of detailed chromatin maps.

\section{HOW FREQUENT ARE PROMOTER REGION METHYLATION CHANGES?}

The increasing recognition of epigenetic changes in cancer has been facilitated by technical advances that allow rapid evaluation of promoter region methylation changes, and by screening techniques that can identify novel targets of epigenetic silencing. Evaluation of methylation patterns is largely dependent on the development of bisulfite-based techniques, first used for genomic bisulfite sequencing mentioned above (Frommer et al. 1992). Conversion of cytosine, but not 5'-methyl-cytosine, to uracil allows the epigenetic change of DNA methylation to be converted to a genetic equivalent, thereby permitting the use of genetic analysis. A wide variety of bisulfite-based techniques can be used to determine methylation patterns of genes under study. These include detailed genomic bisulfite sequencing (Clark et al. 1994), methylation-specific PCR (Herman et al. 1996), which has real-time PCR adaptations (Lo et al. 1999; Eads et al. 2000), and restriction analysis following bisulfite treatment (Sadri and Hornsby 1996; Xiong and Laird 1997). Since methylation-associated gene silencing is a regional change associated with gene silencing, as discussed above, analysis is much simpler than the sequencing of the entire coding region of a gene to search for many different mutations. With these techniques, large numbers of samples can be examined at multiple loci.

\section{IDENTIFICATION OF GENES TARGETED FOR PROMOTER REGION METHYLATION}

The genes studied for promoter region methylation in cancer are derived from three main sources. First, the group of classic tumor suppressor genes, mutated in some cancers, can be silenced in association with promoter region methylation in many other cancers. For example, Rb, Pl6ink4a, MLH1, CDH1, VHL, and BRCA1 are all genes with well-defined increased familial risk of cancer associated with germ-line mutations, and for which transcriptional silencing associated with promoter region hypermethylation has been well documented (Herman and Baylin 2003). For these genes, the importance of epigenetic inactivation is supported by the genetic evidence. It is unlikely that many other familial cancer genes of this type will be identified in the future, however, as these low-prevalence genes associated with extremely high cancer risk have largely already been discovered.

However, many other genes have been examined for promoter region methylation in cancer and appear to have important roles, even though little or no genetic evidence for their function in cancer is known. Genes in this second group have in some cases been identified through regions of allelic loss in cancer where mutational inactivation of the second copy is not found. For example, RASSF1a, a gene commonly methylated and silenced in different types of cancer, was identified from a commonly deleted region of the short arm of chromosome 3 in lung cancer (Dammann et al. 2000). In other cases, pathways regulated by the potentially inactivated gene have been so important that an examination of possible inactivation, including those related to epigenetic changes, has been pursued. This group of genes includes $p 73$, which shares many important regulatory functions with p53 (Jost et al. 1997) and is epigenetically, rather than genetically, inactivated in cancers (Corn et al. 1999; Kawano et al. 1999). Finally, epigenetically inactivated genes derived from knowledge of diminished expression in cancer. For example, the loss of expression of the DNA repair protein methyl-guanine methyltransferase (MGMT) cannot be explained by genetic losses, but rather is due to promoter region methylation changes $(\mathrm{Pa}-$ tel et al. 1997; Esteller et al. 1999).

The recognition of key gene inactivation events playing a role in cancer has led to the development of a number of approaches seeking novel epigenetically silenced genes. Such genome-wide screens either take advantage of methylation-sensitive restriction analysis to find methylated regions in the genome (Liang et al. 1998; Toyota et al. 1999; Costello et al. 2000) or utilize the power of expression analysis using microarrays to find reactivation of silenced genes (Suzuki et al. 2002; Yamashita et al. 2002). Based on the identification of methylation changes through screening approaches, the number of genes methylated in an individual cancer may range in the hundreds (Costello et al. 2000; Suzuki et al. 2002; Yamashita et al. 2002). Given this number, this group of genes represents a challenge for the evaluation of the functional importance of any methylation change, even if clearly associated with loss of gene expression.

\section{FUNCTIONAL SIGNIFICANCE OF PROMOTER METHYLATION}

For both genes without mutational inactivation and those identified through screening approaches, however, gene function remains a key component in determining the role that epigenetic changes in the promoter region of a novel gene play in the cancer phenotype. Many of the 
- Cell cycle control

- Rb, p16, p15, p14, p73, CHFR

- DNA damage

- MLH1, O ${ }^{6} M G M T, G S T \pi$, BRCA1, Fanconi-F

- Apoptosis

- DAP-kinase, Caspase-8, ASC/TMS-1

- Invasion

- E-cadherin, VHL, APC, LKB1, TIMP3, THBS1, H-cad

- Growth factor response

- ER, RAR,$A R$, SOCS-1, RASSF1a, CRBP, SHP1

- SFRP1, SFRP2, SFRP5

- Transcription Factors/Repressors

- HIC1, PAX5 $\alpha$, PAX5 $\beta$, AP2, GATA4, GATA5, CDX2

Figure 1. Promoter region hypermethylation targets critical pathways in human cancer. Promoter region methylation and gene silencing have been demonstrated for these genes in cancer, with resulting alteration in these pathways.

key genes studied extensively for epigenetic silencing in cancer fall into key pathways involved in the malignant phenotype. A select list of such pathway alterations and epigenetically inactivated genes associated with these functions is presented in Figure 1. These involve cell cycle control, DNA repair, apoptosis, and other critical pathways involved in maintaining the normal cell phenotype. The classification of these alterations is in part derived from the well-accepted model of the hallmarks of cancer (Hanahan and Weinberg 2000).

\section{SILENCING OF REGULATORY GENES MAY GLOBALLY AFFECT THE CELL PHENOTYPE}

As discussed above, there may be technical advantages in searching for genes methylated in cancer which lead to identification of increased numbers of hypermethylated genes in cancer. However, there may be additional, nontechnical reasons for the large number of reported epigenetic changes in cancer. Although the exact relationship between the number of epigenetic and genetic changes in cancer will not be understood until work in the Cancer Genome Project is complete, providing a comprehensive genetic and hopefully epigenetic map of the cancer genome of specific cancers, it is possible that the number of epigenetic changes in a given cancer exceeds the number of genetic changes. Epigenetic changes are a very powerful modulator of cellular phenotype, as demonstrated by the profound differences in function of differentiated tissues from different organs.

As an example of this normal modulator of the cell phenotype, the wide variety of histological differentiation observed during embryogenesis is mediated through epigenetic mechanisms, not genetic alterations. Tissues of different origins share the same genotype, and the heritable differences in gene expression must be a reflection of epigenetic changes. It is perhaps interesting to speculate that the abnormal gene silencing due to promoter region methylation observed in cancer represents a normal process gone bad; that is, the normal tissue-specific silencing of genes is abnormally utilized by the cancer precursor cell to produce the transformed phenotype. In contrast, the importance of maintenance of the correct DNA sequence prior to and during DNA replication is reflected by the accuracy of DNA polymerases and the comprehensive and redundant mechanisms for DNA repair pathways that function in human cells (Shcherbakova et al. 2003).

One of the most comprehensive ways to alter a cell phenotype, however, is to alter the expression of genes regulating the expression of other genes. In this case, loss of expression of a transcription factor, for example, would result in altered expression of many downstream target genes. Therefore, it is of interest to note the growing list of recently identified transcription factors that are epigenetically silenced in cancers (Fig. 1). Discussed extensively by Stephen Baylin (Baylin and Chen, this volume) is the HIC-1 gene, a frequently methylated gene in many cancers that can regulate the expression of critical downstream target genes by acting as a transcriptional repressor. Loss of such repressors could lead to increased expression of critical genes, including SIRT1. Also of note are AP2 (Douglas et al. 2004), PAX5 (Palmisano et al. 2003), and GATA4 and GATA5 (Akiyama et al. 2003), all transcription factors potentially modulating the expression of numerous target genes. We have recently determined the methylation-associated silencing of another key transcription factor that modulates the intestinal phenotype. CDX2 is hypermethylated and silenced in certain esophageal cancers, potentially leading to reprogramming of the differentiation of these cells. Loss of CDX2 is associated with loss of the MUC2 gene, normally associated with the adenocarcinoma phenotype.

\section{EPIGENETIC SILENCING AFFECTS MULTIPLE GENES IN INDIVIDUAL TUMORS}

Epigenetic silencing can, of course, affect multiple genes within each cancer. Therefore, studies directed at individual loci, although critical for the initial understanding of the role of gene inactivation in these cancers, do not establish this event in the context of the multiple other genetic and epigenetic changes present in a cancer. Indeed, by looking at multiple genes in individual cancers, it can be seen that the majority of cancers contain many aberrantly methylated $\mathrm{CpG}$ islands that silence many critical genes (Esteller et al. 2001; Toyota et al. 2001; Chim et al. 2003). These epigenetic profiles differ according to tissue of origin of the cancer and the divergent pathological differentiation followed. In examination of a rarely studied tumor, primary CNS lymphoma, we find frequent methylation of genes involved in cell cycle control, DNA repair, and apoptosis, as well as growth factor response, encompassing each of the fundamental pathways shown in Figure 1. The genes silenced in this malignancy are similar to those found in other nonHodgkin's lymphomas and Burkitt's lymphoma. Multiple epigenetic changes cooperate to transform a cell from the normal to the transformed state.

\section{EPIGENETIC PROGRESSION OF CANCER}

The number of changes observed in these tumors offers another advantage in studying the biology of neoplasia. 


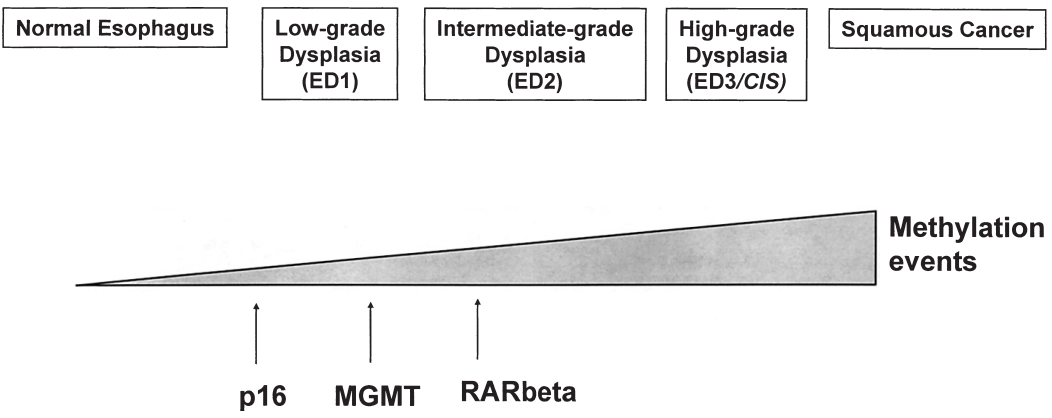

Figure 2. A model for the epigenetic progression of the histological changes found in the development of squamous cell carcinoma. Increases in frequency at individual loci occur as the lesions become more abnormal. In addition, the overall number of genes with aberrant methylation increases as histological atypia increase.

Carcinogenesis is a multistep process that has been described in terms of a tumor progression model, most extensively in the genetic changes found in colon cancer (Vogelstein and Kinzler 1993). We have recently examined the changes in promoter region methylation at multiple loci of invasive tumors, normal tissues, and preinvasive lesions from these same tissues. As an example, the well-defined histology progression of esophageal cancer provides an opportunity to correlate histological progression with molecular progression. The genes targeted for inactivation include those regulating key pathways, as noted in Figure 1. The timing of these events appears to vary, much as has been observed for the genetic models of tumor progression. However, the number of changes present in a lesion increases as the histological changes worsen. We suggest that these observations represent the epigenetic progression that parallels histological progression observed in tumors derived from many organ sites. This is shown in Figure 2.

Because of the frequency and timing of these epigenetic changes, promoter hypermethylation events provide one of the most promising markers for molecular detection of early cancer. DNA-based markers have advantages because of the inherent stability of DNA compared with RNA and some proteins. In addition, the molecular progression observed in many cancers suggests that epigenetic changes might be used to predict progression of preinvasive to invasive cancer, a hypothesis being tested in the preinvasive condition, Barrett's esophagus.

\section{CONCLUSION}

In conclusion, extensive work over the last decade by investigators has demonstrated that epigenetic changes, in addition to the previously defined genetic alterations, are a key component in the development and progression of human cancer. Important regulatory pathways are altered by the silencing of genes with tumor suppressor features, and individual cancers normally have promoter region methylation affecting multiple genes. Screening strategies will uncover new targets of epigenetic silencing, for which the evaluation of functional importance will be needed. The development of epigenetic changes parallels the histological progression, suggesting that many of the phenotypic changes observed histologically are driven by underlying changes in gene expression. The frequency and timing of altered DNA methylation suggest that they may be markers of disease and disease progression.

\section{REFERENCES}

Akiyama Y., Watkins N., Suzuki H., Jair K.W., van Engeland M., Esteller M., Sakai H., Ren C.Y., Yuasa Y., Herman J.G., and Baylin S.B. 2003. GATA-4 and GATA-5 transcription factor genes and potential downstream antitumor target genes are epigenetically silenced in colorectal and gastric cancer. Mol. Cell. Biol. 23: 8429 .

Baylin S.B., Esteller M., Rountree M.R., Bachman K.E., Schuebel K., and Herman J.G. 2001. Aberrant patterns of DNA methylation, chromatin formation and gene expression in cancer. Hum. Mol. Genet. 10: 687.

Bird A.P. 1986. CpG-rich islands and the function of DNA methylation. Nature 321: 209.

Cameron E.E., Baylin S.B., and Herman J.G. 1999a. $\mathrm{p} 15$ (INK4B) $\mathrm{CpG}$ island methylation in primary acute leukemia is heterogeneous and suggests density as a critical factor for transcriptional silencing. Blood 94: 2445.

Cameron E.E., Bachman K.E., Myohanen S., Herman J.G., and Baylin S.B. 1999b. Synergy of demethylation and histone deacetylase inhibition in the re-expression of genes silenced in cancer. Nat. Genet. 21: 103.

Chim C.S., Wong S.Y., and Kwong Y.L. 2003. Aberrant gene promoter methylation in acute promyelocytic leukaemia: profile and prognostic significance. Br. J. Haematol. 122: 571.

Clark S.J., Harrison J., Paul C.L., and Frommer M. 1994. High sensitivity mapping of methylated cytosines. Nucleic Acids Res. 22: 2990.

Corn P.G., Kuerbitz S.J., van Noesel M.M., Esteller M., Compitello N., Baylin S.B., and Herman J.G. 1999. Transcriptional silencing of the p73 gene in acute lymphoblastic leukemia and Burkitt's lymphoma is associated with $5^{\prime} \mathrm{CpG}$ island methylation. Cancer Res. 59: 3352.

Costello J.F., Fruhwald M.C., Smiraglia D.J., Rush L.J., Robertson G.P., Gao X., Wright F.A., Feramisco J.D., Peltomaki P., Lang J.C., Schuller D.E., Yu L., Bloomfield C.D., Caligiuri M.A., Yates A., Nishikawa R., Su Huang H., Petrelli N.J., Zhang X., O'Dorisio M.S., Held W.A., Cavenee W.K., and Plass C. 2000. Aberrant CpG-island methylation has non-random and tumour-type-specific patterns. Nat. Genet. 24: 132.

Dammann R., Li C., Yoon J.H., Chin P.L., Bates S., and Pfeifer G.P. 2000. Epigenetic inactivation of a RAS association domain family protein from the lung tumour suppressor locus 3p21.3. Nat. Genet. 25: 315.

Douglas D.B., Akiyama Y., Carraway H., Belinsky S.A., Esteller M., Gabrielson E., Weitzman S., Williams T., Herman 
J.G., and Baylin S.B. 2004. Hypermethylation of a small CpGuanine-rich region correlates with loss of activator protein-2alpha expression during progression of breast cancer. Cancer Res. 64: 1611.

Eads C.A., Danenberg K.D., Kawakami K., Saltz L.B., Blake C., Shibata D., Danenberg P.V., and Laird P.W. 2000. MethyLight: A high-throughput assay to measure DNA methylation. Nucleic Acids Res. 28: e32.

Esteller M., Hamilton S.R., Burger P.C., Baylin S.B., and Herman J.G. 1999. Inactivation of the DNA repair gene O6methylguanine-DNA methyltransferase by promoter hypermethylation is a common event in primary human neoplasia. Cancer Res. 59: 793.

Esteller M., Fraga M.F., Guo M., Garcia-Foncillas J., Hedenfalk I., Godwin A.K., Trojan J., Vaurs-Barriere C., Bignon Y.J., Ramus S., Benitez J., Caldes T., Akiyama Y., Yuasa Y., Launonen V., Canal M.J., Rodriguez R., Capella G., Peinado M.A., Borg A., Aaltonen L.A., Ponder B.A., Baylin S.B., and Herman J.G. 2001. DNA methylation patterns in hereditary human cancers mimic sporadic tumorigenesis. Hum. Mol. Genet. 10: 3001.

Fahrner J.A., Eguchi S., Herman J.G., and Baylin S.B. 2002. Dependence of histone modifications and gene expression on DNA hypermethylation in cancer. Cancer Res. 62: 7213.

Frommer M., McDonald L.E., Millar D.S., Collis C.M., Watt F., Grigg G.W., Molloy P.L., and Paul C.L. 1992. A genomic sequencing protocol that yields a positive display of 5-methylcytosine residues in individual DNA strands. Proc. Natl. Acad. Sci. 89: 1827.

Hanahan D. and Weinberg R.A. 2000. The hallmarks of cancer. Cell 100: 57.

Herman J.G. and Baylin S.B. 2003. Gene silencing in cancer in association with promoter hypermethylation. N. Engl. J. Med. 349: 2042.

Herman J.G., Graff J.R., Myohanen S., Nelkin B.D., and Baylin S.B. 1996. Methylation-specific PCR: A novel PCR assay for methylation status of $\mathrm{CpG}$ islands. Proc. Natl. Acad. Sci. 93: 9821.

Jones P.A. and Baylin S.B. 2002. The fundamental role of epigenetic events in cancer. Nat. Rev. Genet. 3: 415.

Jost C.A., Marin M.C., and Kaelin W.G., Jr. 1997. p73 is a human p53-related protein that can induce apoptosis. Nature 389: 191.

Kamb A., Gruis N.A., Weaver-Feldhaus J., Liu Q., Harshman K., Tavtigian S.V., Stockert E., Day R.S., III, Johnson B.E., and Skolnick M.H. 1994. A cell cycle regulator potentially involved in genesis of many tumor types. Science 264: 436.

Kawano S., Miller C.W., Gombart A.F., Bartram C.R., Matsuo Y., Asou H., Sakashita A., Said J., Tatsumi E., and Koeffler H.P. 1999. Loss of p73 gene expression in leukemias/lym- phomas due to hypermethylation. Blood 94: 1113 .

Liang G., Salem C.E., Yu M.C., Nguyen H.D., Gonzales F.A., Nguyen T.T., Nichols P.W., and Jones P.A. 1998. DNA methylation differences associated with tumor tissues identified by genome scanning analysis. Genomics 53: 260 .

Lo Y.M., Wong I.H., Zhang J., Tein M.S., Ng M.H., and Hjelm N.M. 1999. Quantitative analysis of aberrant p16 methylation using real- time quantitative methylation-specific polymerase chain reaction. Cancer Res. 59: 3899.

Merlo A., Herman J.G., Mao L., Lee D.J., Gabrielson E., Burger P.C., Baylin S.B., and Sidransky D. 1995. 5' CPG island methylation is associated with transcriptional silencing of the tumour suppressor P16/CDKN2/MTS1 in human cancers. Nat. Med. 1: 686.

Palmisano W.A., Crume K.P., Grimes M.J., Winters S.A., Toyota M., Esteller M., Joste N., Baylin S.B., and Belinsky S.A. 2003. Aberrant promoter methylation of the transcription factor genes PAX5 alpha and beta in human cancers. Cancer Res. 63: 4620.

Patel S.A., Graunke D.M., and Pieper R.O. 1997. Aberrant silencing of the $\mathrm{CpG}$ island-containing human O6-methylguanine DNA methyltransferase gene is associated with the loss of nucleosome-like positioning. Mol. Cell. Biol. 17: 5813.

Sadri R. and Hornsby P.J. 1996. Rapid analysis of DNA methylation using new restriction enzyme sites created by bisulfite modification. Nucleic Acids Res. 24: 5058.

Shcherbakova P.V., Bebenek K., and Kunkel T.A. 2003. Functions of eukaryotic DNA polymerases. Sci. Aging Knowledge Environ. 2003: RE3.

Suzuki H., Gabrielson E., Chen W., Anbazhagan R., Van Engeland M., Weijenberg M.P., Herman J.G., and Baylin S.B. 2002. A genomic screen for genes upregulated by demethylation and histone deacetylase inhibition in human colorectal cancer. Nat. Genet. 31: 141

Toyota M., Kopecky K.J., Toyota M.O., Jair K.W., Willman C.L., and Issa J.P. 2001. Methylation profiling in acute myeloid leukemia. Blood 97: 2823.

Toyota M., Ho C., Ahuja N., Jair K.W., Li Q., Ohe-Toyota M., Baylin S.B., and Issa J.P. 1999. Identification of differentially methylated sequences in colorectal cancer by methylated CpG island amplification. Cancer Res. 59: 2307.

Vogelstein B. and Kinzler K.W. 1993. The multistep nature of cancer. Trends Genet. 9: 138.

Xiong Z. and Laird P.W. 1997. COBRA: A sensitive and quantitative DNA methylation assay. Nucleic Acids Res. 25: 2532.

Yamashita K., Upadhyay S., Osada M., Hoque M.O., Xiao Y., Mori M., Sato F., Meltzer S.J., and Sidransky D. 2002. Pharmacologic unmasking of epigenetically silenced tumor suppressor genes in esophageal squamous cell carcinoma. Cancer Cell 2: 485. 


\title{
$8_{8}^{\infty} \mathrm{CSH} \&$ Cold Spring Harbor Symposia SYMPOSIA on Quantitative Biology
}

\section{Epigenetic Changes in Cancer and Preneoplasia}

\author{
J.G. HERMAN
}

Cold Spring Harb Symp Quant Biol 2005 70: 329-333

Access the most recent version at doi:10.1101/sqb.2005.70.036

References This article cites 36 articles, 15 of which can be accessed free at: http://symposium.cshlp.org/content/70/329.full.html\#ref-list-1

\section{License}

Email Alerting Receive free email alerts when new articles cite this article - sign up in Service the box at the top right corner of the article or click here. 